\title{
Millennium Development Goals: update from North America
}

\author{
Elizabeth Peacock-Chambers, Michael Silverstein
}

Department of Pediatrics, Boston Medical Center, Boston, Massachusetts, USA

\section{Correspondence to} Dr Michael Silverstein, Department of Pediatrics, Boston Medical Center, Vose 3, 88 E Newton St, Boston, MA 02118, USA; michael.silverstein@bmc.org

Received 19 August 2014 Revised 16 October 2014 Accepted 17 October 2014
In the past 15 years, North America made significant advances towards the Millennium Development Goal (MDG) targets despite a crippling and global financial crisis beginning in 2008. The three countries making up North America-Canada, the USA and Mexico-aspired to reach MDGs under strikingly different political and cultural contexts; yet within their own countries, they all face the common challenge of reducing the disparities that exist in education, employment and health across socioeconomic, racial and gender spectrums.

\section{MDG1: POVERTY AND HUNGER}

Progress towards reduction of disparities in poverty and hunger is evident in North America. Mexico met its goal to cut in half the percentage of people living off $<\$ 1.25$ per day 3 years before the anticipated date. This reduction is consistent with the change in percentage of people living in poverty across Latin America, decreasing from 12\% in 1990 to $6 \%$ in 2010. Middle-income countries, however, including Mexico, Argentina, Brazil, Chile and Peru, are largely responsible for this change.

The USA achieved a historic change in the lives of people living in poverty with the adoption in 2010 of the Affordable Care Act (ACA) providing access to healthcare for all citizens. ACA will improve healthcare access; however, it will not impact nonmedical factors, such as poverty, driving poor health outcomes in the USA. Income inequality in the USA and Mexico is currently at an all-time high and remains significantly higher than in European countries or Canada. Living in regions with high-income inequality is associated with an excess risk of premature death independent of individual socioeconomic status, $11 \%$ excess risk in the USA and $38 \%$ in Mexico compared with countries with low-income inequality. ${ }^{1}$ Thus, although poverty reduction is a crucial component of strategies to improve future health outcomes in this region, such strategies also need to address the related issue of income inequality.

Chronic hunger in North America is surprisingly common, yet it presents in nuanced ways. The percentage of underweight children remains low, $<5 \%$ across all North American countries, while the rates of obesity are increasing among children as well as adults. Mexico and the USA are among the 10 countries in the world with highest rates of obesity. Studies in these countries show that food insecurity is associated with both underweight and overweight status, suggesting the need for a shift in the political understanding of malnutrition. ${ }^{2}$ The trends seen in North America may be a foreshadowing for countries with growing economies such as China and India.

\section{MDG3: PROMOTE GENDER EQUALITY}

The most impressive evidence of the promotion of gender equality and empowerment of women is the increasing ratio of women to men in higher education over the past 15 years. Mexico saw an increase from 0.73 in 1990 to 0.97 in $2012,{ }^{3}$ though disparities between rural and urban areas remain prominent. In the USA, women earn a greater proportion of bachelor degrees than men. Black and Hispanic men and women, however, earn a disproportionately low number of those degrees compared with white and Asian populations. Within the workforce, women still receive lower wages compared with men and are more likely to take on vulnerable or unpaid work.

Violence against women continues to exist as a prominent barrier to the empowerment of women. We now have a greater understanding of the impact of trauma exposure on women and children. For example, $40 \%$ of women experiencing intimate partner violence live with children and these children are at greater risk of adverse physical and mental health outcomes as well as child maltreatment and academic failure. ${ }^{4}$ This common form of genderbased violence, therefore, perpetuates crossgenerational cycles of poor health, low educational attainment and poverty.

\section{MDG4: REDUCE CHILD MORTALITY}

Under-five mortality rates in North America remain relatively low. North America also contributed to reductions in under-five mortality globally through vaccination and nutrition programmes. In 2007, Canada led the Catalytic Initiative to Save a Million Lives with the goal of reducing child and maternal mortality. This initiative supported integrated health system strengthening throughout Africa, training 53000 local health workers and providing 5.5 million individual treatments by 2013 .

In North America, a high proportion of deaths among children under the age of 5 years occurs in the neonatal period and is often related to prematurity. Non-Hispanic black women in the USA experience more than double the infant mortality rate compared with white women, exemplifying the disparities that persist. However, among high-income families, North America also saw a paradoxical shift in the recent years with respect to rejection of evidence-based preventative medicine such as vaccinations. Despite the fact that the measles vaccines averted over 10 million deaths worldwide since the year 2000, the USA saw a record 539 measles cases in the first 6 months of the year 2014 alone. This is the highest number of cases since the elimination of measles in the USA in 2000.

Furthermore, North America, the USA in particular, experiences different threats to child safety than 
seen in the rest of the developed world. For example, death among children from firearms is 56 times more common in the USA compared with the UK. ${ }^{5}$ Gun deaths received special attention in the USA after memorable tragedies such as the Sandy Hook Elementary School shooting, although gun violence, particularly among disadvantaged youth, is not a new problem. Nonetheless, this recent attention spurred political interest in the area of firearm control though no significant legislative changes have been made.

\section{MDG5: IMPROVE MATERNAL HEALTH}

Over the past 15 years, significant progress has been made to improve access to reproductive health for all women in North America. The introduction of Plan B, emergency contraception, provided women with an additional safeguard against unplanned pregnancy. Long-acting reversible contraceptives, such as implantable and intrauterine devices, eliminate many of the barriers encountered with oral contraceptive pills or barrier contraception. Yet, access to these new modalities is far from universal based again on socioeconomic status as well as religious affiliations. For example, as recently as June 2014, the Supreme Court of the United States ruled that for-profit employers with religious objections could choose to opt out of providing contraception insurance coverage for their employees under ACA.

\section{MOVING TOWARDS 2020}

North America, like the rest of the world, made progress towards achieving the targets set out by MDGs despite significant economic challenges. Ensuring equitable gains across the socio-demographic spectrum and reducing income inequality remain the challenges of the next 5 years. In many ways, the threats to the health and prosperity of the most vulnerable members of North American society are evolving. Issues such as obesity, gun violence, intimate partner violence and counterculture movements are among some of the urgent challenges facing these developed nations. The North American experience may provide guidance for developing nations facing increasing hardship and morbidity from non-communicable diseases. In the next 5 years, North America must thoughtfully address domestic health disparities and the promotion of gender equality in order to maintain the momentum of the past two decades.

Competing interests None.

Provenance and peer review Commissioned; internally peer reviewed.

\section{REFERENCES}

1 Kondo N, Sembajwe G, Kawachi I, et al. Income inequality, mortality, and self rated health: meta-analysis of multilevel studies. BMJ 2009;339:b4471.

2 Hunger and Obesity: Understanding a Food Insecurity Paradigm: Workshop Summary. Washington, DC, 2011.

3 The Millennium Development Goals in Mexico Progress Report 2013 Executive Summary. 2013. http://200.23.8.225/odm/doctos/Res/nfMex2013_ing.pdf

4 Cruz M, Randell KA, Bair-Merritt MH, et al. Children outcomes and intimate partner violence research. Lancet 2013;382:1326.

5 Murch H, Heatman B, Naughton A, et al. Epidemiology of paediatric firearm injuries. Arch Dis Child 2014;99:790. 